Article

\title{
The Negative Regulative Roles of BdPGRPs in the Imd Signaling Pathway of Bactrocera dorsalis
}

\author{
Ping Zhang ${ }^{\dagger}$, Zhichao Yao $^{\dagger}$, Shuai Bai and Hongyu Zhang *D \\ State Key Laboratory of Agricultural Microbiology, Institute of Urban and Horticultural Entomology, \\ College of Plant Science and Technology, Huazhong Agricultural University, Wuhan 430070, China; \\ 15927410478@163.com (P.Z.); yzc19880118@sina.com (Z.Y.); 15764278717@163.com (S.B.) \\ * Correspondence: hongyu.zhang@mail.hzau.edu.cn; Tel.: +86-27-87286962; Fax: +86-27-87384670 \\ † These authors contributed equally to this work.
}

Citation: Zhang, P.; Yao, Z.; Bai, S.; Zhang, $H$. The Negative Regulative Roles of BdPGRPs in the Imd Signaling Pathway of Bactrocera dorsalis. Cells 2022, 11, 152. https:// doi.org/10.3390/cells11010152

Academic Editor: Alessandro Pogg

Received: 23 November 2021

Accepted: 24 December 2021

Published: 4 January 2022

Publisher's Note: MDPI stays neutral with regard to jurisdictional claims in published maps and institutional affiliations.

Copyright: (C) 2022 by the authors. Licensee MDPI, Basel, Switzerland. This article is an open access article distributed under the terms and conditions of the Creative Commons Attribution (CC BY) license (https:// creativecommons.org/licenses/by/ $4.0 /)$.
Abstract: Peptidoglycan recognition proteins (PGRPs) are key regulators in insects' immune response, functioning as sensors to detect invading pathogens and as scavengers of peptidoglycan (PGN) to reduce immune overreaction. However, the exact function of PGRPs in Bactrocera dorsalis is still unclear. In this study, we identified and functionally characterized the genes BdPGRP-LB, BdPGRP-SB and $B d P G R P-S C_{2}$ in $B$. dorsalis. The results showed that BdPGRP-LB, BdPGRP-SB 1 and $B d P G R P-S C_{2}$ all have an amidase-2 domain, which has been shown to have $N$-Acetylmuramoyl-L-Alanine amidase activity. The transcriptional levels of $B d P G R P-L B$ and $B d P G R P-S C_{2}$ were both high in adult stages and midgut tissues; $B d P G R P-S B_{1}$ was found most abundantly expressed in the 2nd instar larvae stage and adult fat body. The expression of BdPGRP-LB and BdPGRP-SB 1 and $A M P S$ were significantly up-regulated after injury infected with Escherichia coli at different time points; however, the expression of $B d P G R P-S C_{2}$ was reduced at $9 \mathrm{~h}, 24 \mathrm{~h}$ and $48 \mathrm{~h}$ following inoculation with $E$. coli. By injection of dsRNA, BdPGRP-LB, BdPGRP-SB 1 and $B d P G R P-S C_{2}$ were knocked down by RNA-interference. Silencing of $B d P G R P-L B, B d P G R P-S B_{1}$ and $B d P G R P-S C_{2}$ separately in flies resulted in over-activation of the Imd signaling pathway after bacterial challenge. The survival rate of the $d s-P G R P s$ group was significantly reduced compared with the $d s-e g f p$ group after bacterial infection. Taken together, our results demonstrated that three catalytic PGRPs family genes, BdPGRP-LB, BdPGRP-SB 1 and $B d P G R P-S C_{2}$, are important negative regulators of the Imd pathway in $B$. dorsalis.

Keywords: Imd pathway; PGRPs; bacterial infection; negative regulators; gene identification

\section{Introduction}

Insects come into contact with many kinds of pathogenic microorganisms from their habitat, and therefore insects have involved a strong innate immune system to resist microbial challenge. This system immediately responds against invading pathogens, and consists of cellular and humoral immune responses [1]. The activation of a series of antimicrobial defense mechanisms relies on a microbial sensing system of pattern-recognition receptors (PRRs) [2]. In insects, peptidoglycan recognition proteins (PGRPs) are a major class of PRRs that can recognize peptidoglycan (PGN), the specific component of the cell wall in both Gram-positive and Gram-negative bacteria [3,4]. PGN is a polymer with alternating $\mathrm{N}$-acetylglucosamine and $\mathrm{N}$-acetylmuramic acid residues that are cross-linked to each other by short peptide bridges; Gram-negative bacteria and Gram-positive Bacilli have DAP type PGN, unlike Gram-positive bacteria, which have Lys type PGN [5,6]. PGRP was first discovered in silkworms (Bombyx mori) in the late 1990s. PGRP was confirmed to have the ability to trigger a series of prophenoloxidase cascades after binding to different types of peptidoglycans [7]. With the progress of genome projects for different species, PGRP and its homologues have been identified in animals ranging from insects to mammals [8-11]. PGRPs are highly conserved from insects to mammals, which share a conserved 160 amino 
acid domain with similarities to the bacteriophage T7 lysozyme, a zinc-dependent amidase that hydrolyzes peptidoglycan [4].

Studies of PGRPs have focused on D. melanogaster. Drosophila has 13 PGRP genes which can encode 20 PGRP proteins; PGRPs can be divided into catalytic PGRPs and non-catalytic PGRPs according to their function [8]. Noncatalytic PGRPs (PGRP-SA, SD, LA, LC, LD, LE and LF) can only bind to peptidoglycan and lack amidase activity due to the absence of key cysteine residues for zinc binding, which are crucial for sensing of bacteria and activating immune pathways in the immune system. By contrast, catalytic PGRPs (PGRP$\mathrm{SC} 1 \mathrm{a} / \mathrm{b}, \mathrm{SC}_{2}, \mathrm{LB}$ and $\mathrm{SB}_{1 / 2}$ ) hydrolyze peptidoglycan by cleaving the amide bond between MurNAc and the peptidic bridge, leading to a termination of immune response [12,13]. The amidase PGRPs function as key immunoregulatory factors, regulating the immune response by cleaving peptidoglycan and existing directly as a bactericide [14]. In D. melanogaster, amidase PGRPs reduce the expression level of AMPs by degrading peptidoglycan and downregulating the immune response [13]. PGRP-LB deletion mutant and Pirk deletion mutant, and to a lesser extent $P G R P$-SC single deletion mutant flies showed reductions in mean lifespan compared to wild-type after Ecc15 (Erwinia carotovora carotovora 15) infection. The excessive death of null mutants was due to their own excessive immune response rather than the accumulation of conditional pathogens, which has been further confirmed in [13]. $D m P G R P-L B$ with amidase can downregulate the immune response by converting the Gram negative PGN to non-immunostimulatory fragments [6]. DmPGRP-SC $C_{2}$ was inhibited by FOXO with age, leading to immune system disorders and intestinal microbial disorders [15]. $D m P G R P-S B_{1}$ has an amidase activity against DAP-type PGN, while DmPGRP-SB 1 and $S B_{2}$ are, at most, only marginally involved in the regulation of the Imd pathway [13,16].

The oriental fruit fly Bactrocera dorsalis (Hendel) is a destructive polyphagous and invasive insect pest of tropical and subtropical fruits and vegetables [17]. Owing to its vast adaptability, high reproduction potential and invasive capacity, B. dorsalis has been one of the world's most invasive and polyphagous pests of agriculture [18]. B. dorsalis larvae live in rotten fruits and are more likely to be exposed to pathogenic bacteria. Indeed, $B$. dorsalis is emerging as a good material for research into immunity $[19,20]$ and the role of immunity in microbiota homeostasis [21]. Although the functions of PGRPs have been shown in a number of insects, especially in D. melanogaster [16,22-25] and in other insects such as Musca domestica, Sitophilus zeamais, Rhynchophorus ferrugineus [26-28] as well, there is no clear picture of the role of $P G R P S$ in $B$. dorsalis.

In this study, we cloned BdPGRP-LB, one isoform of PGRP-SB (BdPGRP-SB $)_{1}$, and one isoform of $P G R P-S C$ (BdPGRP-SC 2 ). The expression profiles of the BdPGRP-LB, BdPGRP-SB 1 and $B d P G R P-S C_{2}$ genes in different developmental stages and adult tissues were examined by real-time quantitative polymerase chain reaction (qRT-PCR). We monitored the immune response of $B d P G R P S$ after adults were infected with the Gram-negative bacteria $E$. coli, and revealed the important negative roles of the BdPGRP-LB, BdPGRP-SB $B_{1}$ and $B d P G R P-S C_{2}$ genes in the Imd pathway of $B$. dorsalis using RNA interference methods.

\section{Materials and Methods}

\subsection{Experimental Insects}

B. dorsalis was collected from Guangzhou, China and reared more than 20 generations at the Institute of Urban and Horticultural Pests at Huazhong Agricultural University, Wuhan, as described by Li et al. [17]. The newly emerged adults were reared in cages under the following conditions: $28 \pm 1{ }^{\circ} \mathrm{C}, 70-80 \%$ relative humidity, $12 \mathrm{~h} / 12 \mathrm{~h}$ light/dark cycle; adults' artificial diet contained $2.5 \%$ yeast extract, $7.5 \%$ sugar, $2.5 \%$ honey, $0.5 \%$ agar and $87 \%$ water; eggs and larvae were fed on bananas.

\subsection{Cloning and Analysis of the BdPGRP Genes}

Total RNA was extracted from B. dorsalis with RNAiso ${ }^{\mathrm{TM}}$ Plus reagent $(\mathrm{TaKaRa}$, Otsu, Shiga, Japan) following the manufacturer's instructions. Ten newly emerged adults of $B$. dorsalis with a sex ration at 1:1 were homogenized in $1 \mathrm{~mL}$ RNAiso with a burnisher (Shang- 
hai Jingxin Industrial Development Co., Ltd., Shanghai, China) at $70 \mathrm{~Hz} / \mathrm{s}$ for $60 \mathrm{~s}$ at $10 \mathrm{~s}$ intervals. The purity of the RNA was analyzed using a NanoDrop 1000 Spectrophotometer (Thermo Fisher Scientific, Waltham, MA, USA) and the quality of RNA was tested by $1.0 \%$ agarose gel electrophoresis at voltage 120 V, 20 min in TAE buffer. First strand cDNA was synthesized from $1 \mu \mathrm{g}$ RNA using the PrimeScript ${ }^{\mathrm{TM}}$ RT reagent Kit with gDNA Eraser Kit (TaKaRa). Then, the cDNA was served as template. The amplification of $3^{\prime}-$ and $5^{\prime}-\mathrm{cDNA}$ ends of BdPGRP-SC 2 was conducted with the $3^{\prime}$-Full RACE Core Set (Cat. \# 6121) (TaKaRa, Otsu, Shiga, Japan) and 5'-Full RACE Kit (Cat. \# 6122) (TaKaRa, Otsu, Shiga, Japan) according to the manufacturer's instructions. Primers for RACE were designed according to the fragment sequence from transcriptome of $B$. dorsalis. The sequence of $B d P G R P-L B$ and $B d P G R P-S B_{1}$ were obtained from the NCBI database (Genebank: GAKP01019367; GAKP01007643). PCR conditions were $94{ }^{\circ} \mathrm{C} 3 \mathrm{~min} ; 94{ }^{\circ} \mathrm{C} 30 \mathrm{~s}, 55^{\circ} \mathrm{C} 30 \mathrm{~s}, 72{ }^{\circ} \mathrm{C} 60 \mathrm{~s}$ for 35 cycles; $72{ }^{\circ} \mathrm{C} 10 \mathrm{~min}$. PCR was carried out in a volume of $25 \mu \mathrm{L}$ consisting of $12.5 \mu \mathrm{L}$ PCR Mix (Biomed, Beijing, China), $100 \mathrm{nM}$ of each primer and $1 \mu \mathrm{g}$ of cDNA. PCR products were purified with AxyPrep DNA Gel Extraction Kit (AXYGEN, Union City, CA, USA) and then cloned into pEASY-T1 Cloning Vector (TransGen, Beijing, China) and sequenced.

The nucleotide and protein sequences were analyzed with DNAMAN 6.0 (Lynnon Corporation, Quebec, QC, Canada). Nucleotide sequence alignment used the blast online tools (https://blast.ncbi.nlm.nih.gov/Blast.cgi (accessed on 18 January 2021)). Amino acid sequence alignment was analysed using DNAMAN software. The functional protein predictions were analyzed using online tools (http:/ / smart.embl-heidelberg.de/smart/ set_mode.cgi (accessed on 18 January 2021)). A phylogenic neighbour-joining (NJ) tree was constructed with the Mega7 software package (Mega, Auckland, New Zealand). The sequence data were transformed into a distance matrix. One thousand bootstraps were performed for the NJ tree to check the repeatability of the results.

\subsection{Development Stage and Tissue Expression Profiles}

The expression profile was analysed by qRT-PCR. Different development stages of B. dorsalis were collected: eggs, first instar larvae, second instar larvae, third instar larvae, early pupae ( $48 \mathrm{~h}$ after pupation), old pupae ( $48 \mathrm{~h}$ before eclosion), adults (sex ration at 1:1) before mating (2-3 days after eclosion), and adults (sex ration at 1:1) after mating (13-15 days after eclosion). For eggs, five independent cohorts of every 50 eggs were collected as biological replicates. For larvae, pupae, and adults, five independent cohorts of every ten individuals were collected as biological replicates. For different tissue collection, the adults (2-3 days after eclosion) were sterilized for 2-5 $\mathrm{min}$ in $75 \%$ alcohol, washed in DEPC-water three times and then dissected in phosphate buffer saline $(137 \mathrm{mM} \mathrm{NaCl}$, $2.7 \mathrm{mM} \mathrm{KCl}, 10 \mathrm{mM} \mathrm{Na}_{2} \mathrm{HPO}_{4}, 2 \mathrm{mM} \mathrm{KH} \mathrm{PO}_{4}, \mathrm{pH}$ 7.4). The different tissues examined included the head, midgut, hindgut, Malpighian tubule, fat body, ovaries and testes. Five independent cohorts of every 30 flies were dissected and used as biological replicates. All samples were homogenized in $1 \mathrm{~mL}$ RNAiso ${ }^{\mathrm{TM}}$ Plus (TaKaRa, Otsu, Shiga, Japan) as described above, followed by RNA extraction and cDNA synthesis.

\subsection{Bacterial Preparation and Infection Bioassays}

Escherichia coli $\mathrm{DH} 5 \alpha$ used in this experiment were stored in the Institute of Urban and Horticultural Entomology, Huazhong Agricultural University. A Gram-negative bacterium, E. coli has DAP type PGN, and the Imd pathway can be activated by DAP type PGN [29]. E. coli were cultivated in $400 \mathrm{~mL} \mathrm{LB}$ (Luria-Bertani) medium at $37^{\circ} \mathrm{C}$ with shaking $220 \mathrm{r} / \mathrm{min}$ for 3-5 h until the concentration of OD $600=1\left(\sim 5 \times 10^{8}\right.$ colony-forming units (CFUs)), as previous described [21]. Then, the bacteria cultures were centrifuged at $3600 \times g$ for $5 \mathrm{~min}$ at room temperature and washed two times with phosphate buffer saline. For systemic infection, the bacteria pellets were resuspended in LB and adjusted to a certain concentration $(\mathrm{OD} 600=400)$ for infection.

For infection bioassays, 250 newly emerged flies (within three days following eclosion) were collected in boxes. The glass needles which were prepared with a puller at heat level 
60.8 (PC-10, Narishige, Tokyo, Japan) were used to dip into the bacteria pellet (OD600 = 400) or LB medium (the Control) for $30 \mathrm{~s}$, and then the thorax of ice anaesthetized adult flies was inoculated and ten whole body samples were collected at $1 \mathrm{~h}, 3 \mathrm{~h}, 6 \mathrm{~h}, 9 \mathrm{~h}, 12 \mathrm{~h}, 24 \mathrm{~h}$, $48 \mathrm{~h}$ after infection with a sex ratio of 1:1. The experiment was repeated three times.

\subsection{Double Strain RNA Synthesis and RNAi}

PCR amplification was carried out with primers of gene fragments containing T7 polymerase promoter (GGATCCTAATACGACTCACTATAGG). The egfp fragment which was used as a control was also amplified from Pub. nls. EGFP (Provided by Dr. Handler, USDA). The primers used to amplify the specific DNA fragments are listed in Table 1. PCR products were purified with an AxyPrep DNA Gel Extraction Kit (AXYGEN, USA) and then used as the template for double-stranded RNA synthesis by using a T7 RiboMAX ${ }^{\mathrm{TM}}$ Express RNAi System (Promega, Madison, WI, USA) as per the manufacturer's instructions. The dsRNA pellet was resuspended in RNase-free water and quantified at $260 \mathrm{~nm}$ using a Nanodrop 1000 spectrophotometer (Thermo Fisher Scientific, Waltham, MA, USA). The quality of dsRNA was tested by $1.2 \%$ agarose gel electrophoresis at voltage $120 \mathrm{~V}, 20 \mathrm{~min}$ in TAE buffer.

Table 1. Primers used in RT-PCR and qRT-PCR.

\begin{tabular}{|c|c|c|}
\hline Primer & Sequence (from $5^{\prime}$ to $3^{\prime}$ ) & Purpose \\
\hline PGRP-SC2 5'RACE outer & CCTTAGCGGCAGCAATCT & RACE \\
\hline PGRP-SC2 5'RACE inner & CCACGACCCTCATACACT & RACE \\
\hline PGRP-SC2 3'RACE outer & GCAAGTGTATGAGGGTCG & RACE \\
\hline PGRP-SC2 3'RACE inner & TTACTGCTCCACCCAAAC & RACE \\
\hline $\mathrm{QPGRP}-L B \mathrm{~F}$ & GCGTGGCTGGAATGACATTG & qRT-PCR \\
\hline $\mathrm{Q} P G R P-L B \mathrm{R}$ & CGGTCATTGTATTTGGGCGC & qRT-PCR \\
\hline$\widehat{\mathrm{Q}} P G R P-S B \mathrm{~F}$ & TGGCATTGTCTTCATCGGCA & qRT-PCR \\
\hline $\mathrm{Q} P G R P-S B \mathrm{R}$ & CAGATAACCCTTTTGCACCGC & qRT-PCR \\
\hline$\widehat{\mathrm{QP}} \mathrm{PRP}-\mathrm{SC} \mathrm{C}_{2} \mathrm{~F}$ & GGGTCGTGGTTGGAGTACAG & qRT-PCR \\
\hline $\mathrm{Q} P G R P-S C_{2} \mathrm{R}$ & GATCTGAGCGGCTGTTGGAA & qRT-PCR \\
\hline $\mathrm{QRpL32 \textrm {F }}$ & CCCGTCATATGCTGCCAACT & qRT-PCR \\
\hline $\mathrm{QRpL32} \mathrm{R}$ & GCGCGCTCAACAATTTCCTT & qRT-PCR \\
\hline QDiptericin F & GCATAGATTTGAGCCTTGACACAC & qRT-PCR \\
\hline QDiptericin R & GCCATATCGTCCGCCCAAAT & qRT-PCR \\
\hline$P G R P-L B$ T7F & GGATCCTAATACGACTCACTATAGGATGCCCAGCGCCTGTTAC & dsRNA synthesis \\
\hline PGRP-LB T7R & GGATCCTAATACGACTCACTATAGGTGCGGCCACGTCGTAATC & dsRNA synthesis \\
\hline PGRP-SB T7 F & GGATCCTAATACGACTCACTATAGGTGTTTTGCGCTCAGGATCCA & dsRNA synthesis \\
\hline PGRP-SB T7R & GGATCCTAATACGACTCACTATAGGTGGCCCAGCAGTGTGTAATT & dsRNA synthesis \\
\hline$P G R P-S C_{2} \mathrm{~T} 7 \mathrm{~F}$ & GGATCCTAATACGACTCACTATAGGGGCTTTCAAGACTTTCCTC & dsRNA synthesis \\
\hline$P G R P-S C_{2}$ T7R & GGATCCTAATACGACTCACTATAGGAACCACGACCCTCATACAC & dsRNA synthesis \\
\hline EGFP T7L & GGATCCTAATACGACTCACTATAGGACGTAAACGGCCACAAGTTC & dsRNA synthesis \\
\hline EGFP T7R & GGATCCTAATACGACTCACTATAGGAAGTCGTGCTGCTTAATGTG & dsRNA synthesis \\
\hline
\end{tabular}

Primers starting with $\mathrm{Q}$ were used for qRT-PCR; the underlined sections indicate T7 polymerase promoter.

Microinjection was performed using an Eppendorf micromanipulation system (Microinjector for cell biology, FemtoJet 5247, Hamburg, Germany). The injection condition was set to a Pi of $300 \mathrm{hpa}$ and a Ti of $0.3 \mathrm{~s}$. The needles for microinjection were made with a puller at heater level 60.8 (PC-10, Narishige, Tokyo, Japan) as previous described [21]. Each fly (three days after eclosion) was injected with $1 \mu \mathrm{L}$ dsRNA at a concentration of $2000 \mathrm{ng} / \mu \mathrm{L}$ for the gene knockdown experiment. After injection, adult flies were transferred to a $17 \mathrm{~cm} \times 8 \mathrm{~cm} \times 7 \mathrm{~cm}$ plastic box and fed an artificial diet. 


\subsection{Investigation of the RNAi Off-Target Effect and RNAi Efficiency}

Based on sequence similarity, numerous off-targets are predicted to occur in RNAi experiments [30]. $B d P G R P-L B, B d P G R P-S B_{1}$ and $B d P G R P-S C_{2}$ all belong to a PGRP family with high sequence homology. It is critical to investigate the RNAi off-target effect during PGRP gene RNAi experiments. To ensure the other PGRPs transcripts were not affected by one PGRP gene RNAi, the mRNA expression level was examined by qRT-PCR. qRT-PCR was performed with iQTM SYBR ${ }^{\circledR}$ Green Supermix (Bio-Rad, Berkeley, CA, USA) on BioRad iQ5 (Bio-Rad, Berkeley, CA, USA). The $20 \mu \mathrm{L}$ reactions contained $10 \mu \mathrm{L} 2 \times$ Master Mix, $2 \mu \mathrm{L}$ cDNA (diluted 1:10), $0.8 \mu \mathrm{L} 10$ pmol forward and reverse primers and $6.4 \mu \mathrm{L}$ double-distilled water. The PCR program was preincubated at $95^{\circ} \mathrm{C}$ for $3 \mathrm{~min}$ followed by 40 cycles of denaturation at $95^{\circ} \mathrm{C}$ for $10 \mathrm{~s}$ and annealing at $60^{\circ} \mathrm{C}$ for $30 \mathrm{~s}$. When $B d P G R P-L B$ was knocked down at $24 \mathrm{~h}$ after RNAi, the expression of $B d P G R P-S B_{1}$ and $B d P G R P-S C_{2}$ was detected at the same time; when $B d P G R P-S B_{1}$ was knocked down at $24 \mathrm{~h}$ after RNAi, the expression of $B d P G R P-L B$ and $B d P G R P-S C_{2}$ was detected at the same time; and when $B d P G R P-S C_{2}$ was knocked down at $24 \mathrm{~h}$ after RNAi, the expression of BdPGRP-LB and $B d P G R P-S B_{1}$ was detected at the same time.

\subsection{The Effects of Knockdown of BdPGRPs on the Imd Pathway Response to Bacterial Challenge}

To explore the effects of silencing PGRPs in the Imd pathway of B. dorsalis, E. coli were inoculated at $24 \mathrm{~h}$ after RNAi. There were three experimental groups: the control group was inoculated with LB medium $24 \mathrm{~h}$ after injection with $d s-e g f p$; the ds-egfp group was infected with E. coli $(\mathrm{OD} 600=400)$ after injection with $d s-e g f p$; and the $d s-P G R P s$ group was infected with $E$. coli $(\mathrm{OD} 600=400)$ after injection with $d s-P G R P s$. Then, the expression of Dpt, a marker of Imd pathway activation, was detected at $6 \mathrm{~h}, 12 \mathrm{~h}, 24 \mathrm{~h}$ and $48 \mathrm{~h}$ after infection.

\subsection{Survival Assay of B. dorsalis}

$24 \mathrm{~h}$ after dsRNA injection (separately or combined $3 B d P G R P s$ genes), insects that were alive in the control and treatment groups were individually challenged with $E$. coli by inoculation with bacteria resuspended in LB (Luria-Bertani) (refer to bacterial infection bioassays). Infected flies were placed into new boxes and these boxes into thermostatic incubator at $28 \pm 1{ }^{\circ} \mathrm{C}, 70-80 \%$ relative humidity, $12 \mathrm{~h} / 12 \mathrm{~h} \mathrm{light} /$ dark cycle, and fed with artificial diet. The mortality of $B$. dorsalis adults was monitored daily and dead insects were recorded and removed from the boxes.

\subsection{Quantitative Real-Time PCR}

All tested samples of RNA were extracted with RNAiso ${ }^{\mathrm{TM}}$ Plus (TaKaRa) following the manufacturer's instructions; refer to Section 2.2. The purity of the RNA was analyzed using a NanoDrop 1000 Spectrophotometer (Thermo Fisher Scientific Inc., USA) and the quality of RNA was tested by $1.0 \%$ agarose gel electrophoresis at voltage $120 \mathrm{~V}, 20 \mathrm{~min}$ in TAE buffer. cDNA was synthesized using the PrimeScript ${ }^{\mathrm{TM}} \mathrm{RT}$ reagent Kit with gDNA Eraser (TaKaRa). The first-strand complementary DNA (cDNA) of each pool was synthesized from $1 \mu \mathrm{g}$ of total RNA using a two-step cDNA synthesis kit (Takara) with the gDNA eraser to remove residual DNA contamination. qRT-PCR was performed with iQTM SYBR ${ }^{\circledR}$ Green Supermix (Bio-Rad, USA) on Bio-Rad iQ5 (Bio-Rad, USA). The $20 \mu \mathrm{L}$ reactions contained $10 \mu \mathrm{L} 2 \times$ Master Mix, $2 \mu \mathrm{L}$ cDNA (diluted 1:10), $0.8 \mu \mathrm{L} 10$ pmol forward and reverse primers and $6.4 \mu \mathrm{L}$ double-distilled water. The PCR program was preincubated at $95^{\circ} \mathrm{C}$ for $3 \mathrm{~min}$, followed by 40 cycles of denaturation at $95^{\circ} \mathrm{C}$ for $10 \mathrm{~s}$ and annealing at $60^{\circ} \mathrm{C}$ for $30 \mathrm{~s}$. Melting curve analysis was performed at the end of the program to confirm the specificity of the primers. BdRpl32 was chosen as the reference gene. To determine the amplification efficiencies, a standard curve was established for each primer pair with serial dilutions of cDNA $\left(1 / 1,1 / 10,1 / 100,1 / 1000,1 / 10^{4}, 1 / 10^{5}\right)$. Every sample had three technical replicates. The relative gene expression data were analyzed using a $2^{-\Delta \Delta C T}$ method and the data were normalized to the reference gene Rpl32 for mRNA expression analysis [31]. The qPCR primers are listed in Table 1. 


\subsection{Statistical Analyses}

Comparisons between the means of two independent groups were performed with Student's t-test, and multiple comparisons of results from experimental replicates were analyzed by one-way analysis of variance (ANOVA) and Turkey's test using SPSS 16.0 (IBM Corporation, Somers, NY, USA). Survival statistical analysis was based on Log-rank (Mantel-Cox) test. The plots were handled with Excel (Microsoft, Redmond, WA, USA) and GraphPad Prism 7 (GraphPad Software Inc., San Diego, CA, USA).

\section{Results}

\subsection{Sequence Features, Phylogenetic Tree and Functional Domain Prediction of PGRPS} in B. dorsalis

A 564 bp nucleotide fragment of $B d P G R P-S C_{2}$ was obtained by RACE; the GenBank accession number of the fragment of $B d P G R P-S C_{2}$ is MW538960. The gene encoded a 188-amino acid protein. Both amino acid sequence alignment (Figure 1) and protein prediction results (Supplementary Figure S1) indicated that BdPGRP-LB, BdPGRP-SB 1 and $B d P G R P-S C_{2}$ all have a type 2 amidase domain, which has been shown to have $\mathrm{N}$ acetylmuramoyl-L-alanine amidase activity. Amino acid sequence analysis showed that $B d P G R P-L B, B d P G R P-S B_{1}$ and BdPGRP-SC $C_{2}$ all have conserved amino acid Arg, which is necessary for the recognition of DAP-type peptidoglycan [32]. BdPGRP-LB has three conserved histidines, H53, H77, H162, one conserved tryptophan, W83, one conserved tyrosine, Y98 and one conserved threonine, T168, which are required for $\mathrm{Zn}^{2+}$ binding and amidase activity (Figure 1A). BdPGRP-SB 1 has conserved H50, H74, H159 and Y85 for amidase activity (Figure 1B). BdPGRP-SC 2 has conserved H61, H75, H169, W81 and Y86 for $\mathrm{Zn}^{2+}$ binding and amidase activity (Figure $1 C$ ). These results indicate that $B d P G R P-L B$, $B d P G R P-S B_{1}$ and $B d P G R P-S C_{2}$ belong to the catalytic PGRPs. A phylogenetic tree was constructed to determine the evolutionary relationships with PGRPs from several other insect species of Diptera (Supplementary Figure S2). The results show that BdPGRP-LB, $B d P G R P-S B_{1}$ and $B d P G R P-S C_{2}$ from different species converge in a clade; respectively, this indicates that $P G R P-L B, P G R P-S B_{1}$ and $P G R P-S C_{2}$ evolved independently. In addition, all three $B d P G R P$ s of $B$. dorsalis were closest to those of $B$. latifrons in evolution of the three genes (Supplementary Figure S2).

\subsection{The Expression Profilings of BdPGRPs in B. dorsalis}

qPCR was performed to detect the expression pattern of $B d P G R P-L B, B d P G R P-S B_{1}$ and $B d P G R P-S C_{2}$ in different development stages and in various tissues using the primers listed in Table 1. BdPGRPs can be detected across the life stage of $B$. dorsalis, and the expression levels of $B d P G R P-L B, B d P G R P-S B_{1}$ and $B d P G R P-S C_{2}$ were all highly expressed in the adult stage and in the second instar larvae stage (Figure 2A-C), and expressed weakly in the egg, 1st instar larvae, 3rd instar larvae and pupa stages (Figure 2A-C).

Tissue profiles of $B d P G R P-S B_{1}, B d P G R P-L B$ and $B d P G R P-S C_{2}$ were also analyzed by qRT-PCR. In contrast to the weak expression observed in the hindgut and ovary, the $B d P G R P-L B$ and $B d P G R P-S B_{1}$ were primarily distributed in the head, midgut and fatbody (Figure 2D,E). BdPGRP-LB was also highly expressed in the Malpighian tubules (Figure 2D), which are vital immune response-related sites [33]. The high expression of BdPGRP$S B_{1}$ observed in the testis suggested they may have an important role in reproductive development of $B$. dorsalis (Figure 2E). Interestingly, the tissue specific expression indicated that $B d P G R P-S C_{2}$ had higher expression levels in the head and midgut than in other tissues (Figure 2F). The varied expression of BdPGRP-LB, BdPGRP-SB 1 and $B d P G R P-S C_{2}$ in different developmental stage and tissues suggests that $B d P G R P s$ may play distinct roles in B. dorsalis. 
A

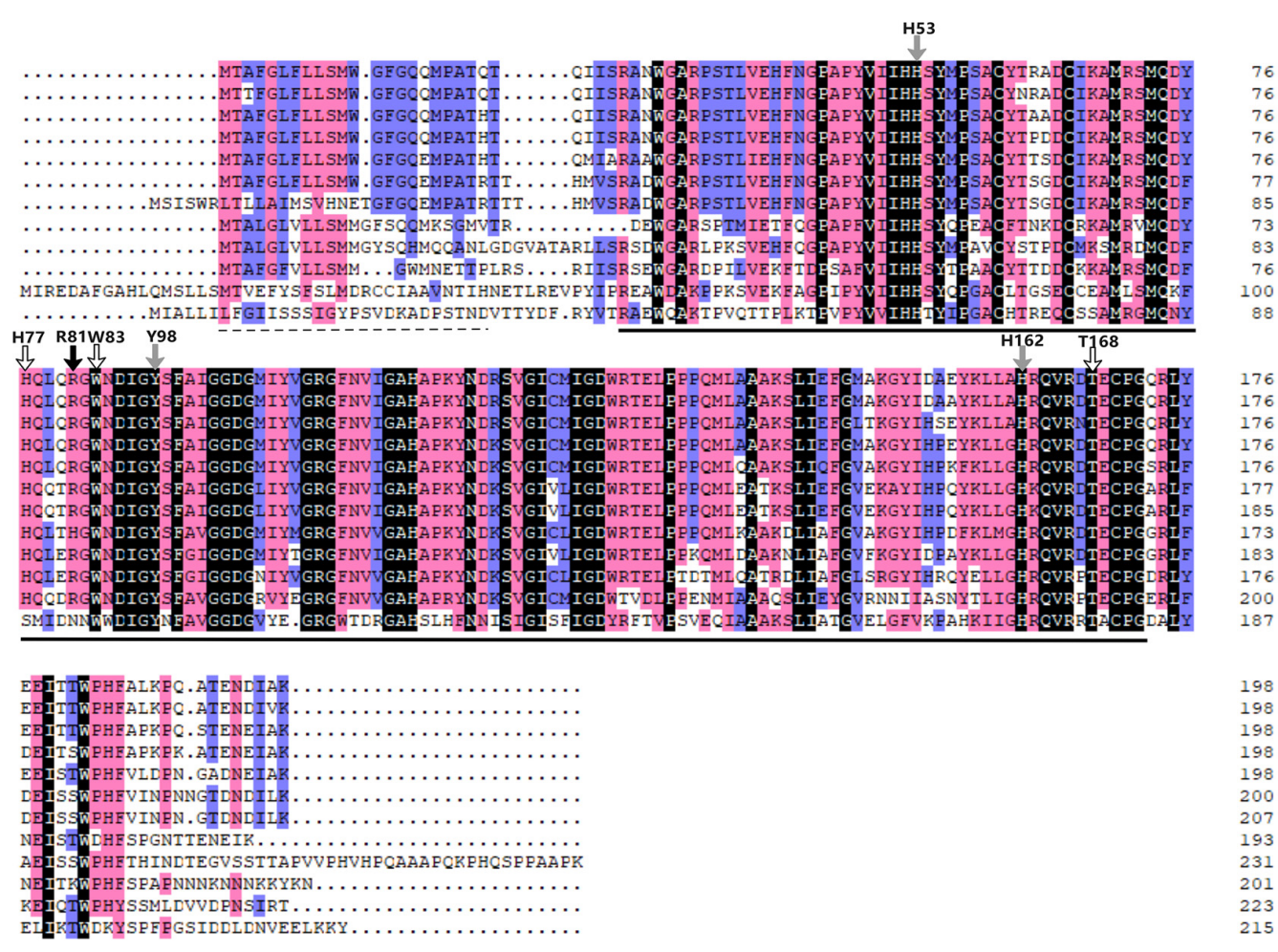

B

BdPGRP-IB
B1PGRP-IB
BoPGRP-IB
ZcPGRP-IB
CCPGRP-IB
RzPGRP-IB
RpPGRP-IB
MdPGRP-IB
DmPGRP-IB
GfPGRP-IB
AaPGRP-IB
BmPGRP-IB

BdPGRP-IB
B1PGRP-IB
BoPGRP-IB
ZCPGRP-IB
CCPGRP-IB
RzPGRP-IB
RpPGRP-IB
MdPGRP-IB
DmPGRP-IB
GfPGRP-IB
AaPGRP-IB
BmPGRP-LB

BdPGRP-IB
B1PGRP-LB
BoPGRP-IB
ZcPGRP-IB
CCPGRP-IB
RzPGRP-IB
RpPGRP-IB
MdPGRP-IB
DmPGRP-IB
GfPGRP-LB
AaPGRP-IB
BmPGRP-LB

BdPGRP-SB 1 B1PGRP-SB ZCPGRP-SB 1 BOPGRP-SBI CCPGRP-SBI RPPGRP-SBI RZPGRP-SBI PAPGP-SB]

BdPGRP-SB 1 B1PGRP-SB ZCPGRP-SB BOPGRP-SB1 CCPGRP-SB RpPGRP-SB Rz PGRP-SB MdPGRP-SB
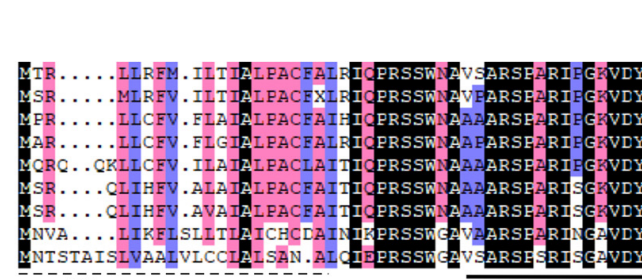

H5

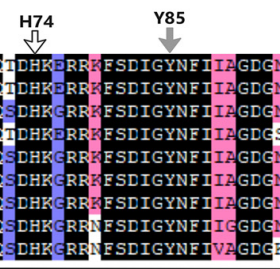

pog

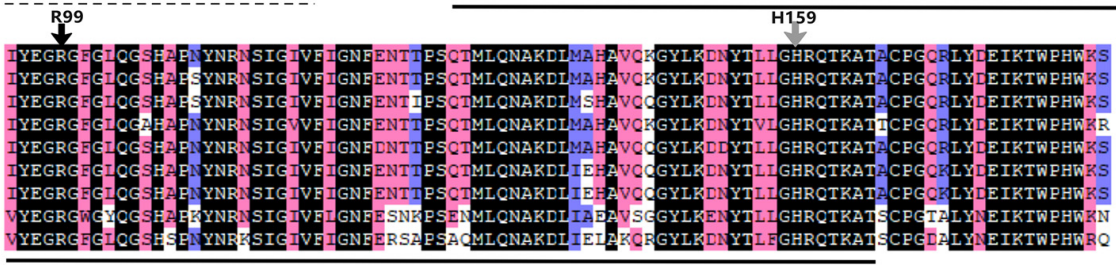

94

C

BdPGRP-SC2 ZCPGRP-SC2 ZCPGRP-SC2 CCPGRP-SC2 RDPGRP-SC2 BOPGRP-SC2 DMPGRP-SC2 MAPGRP-SC2 AaPGRP-SC2

BdPGRP-SC2 ZCPGRP-SC2 2CPGRP-SC2 CIPGRP $-5 C 2$ CORGRP SC2 RPGRP DORRP DMPGRP-SC2 AaPGRP-SC2

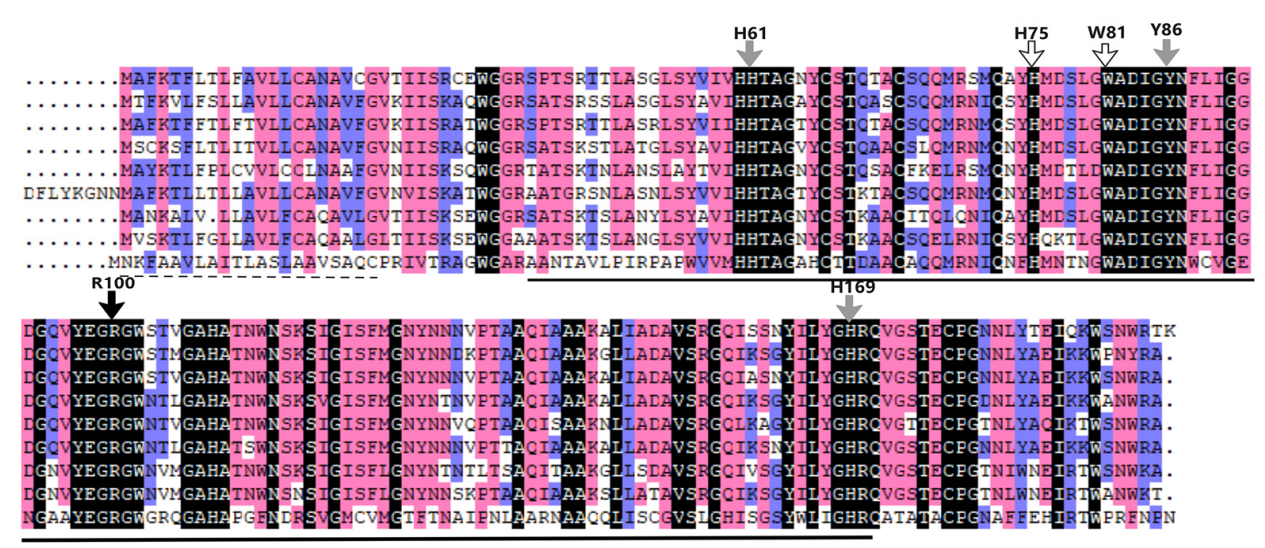

92
92
92
92
92
100
91
92
93

Figure 1. Amino acid sequence alignment of $B d P G R P S$ with that of homologous genes in other 
insect species. (A) Multiple alignments of PGRP-LB. BdPGRP-LB was aligned with Bactrocera latifrons PGRP-LB (XP_018789449.1), Bactrocera oleae PGRP-LB (XP_014091181.2), Zeugodacus cucurbitae PGRP-LB (XP_011197144.1), Ceratitis capitate PGRP-LB (XP_004518089.1), Rhagoletis zephyria PGRP-LB (XP_017470705.1), Rhagoletis pomonella PGRP-LB (XP_036322481.1), Aedes aegypti PGRPLB (XP_021709443.1), Drosophila melanogaster PGRP-LB (NP_731575.1), Bombyx mori PGRP-LB (XP_012548100.1), Musca domestica PGRP-LB (XP_005180889.1), and Glossina fuscipes PGRP-LB (ACI22620.1). (B) Multiple alignments of $P G R P-S B$. BdPGRP-SB 1 was aligned with $B$. latifrons PGRPSB (XP_018789286.1), B. oleae PGRP-SB (XP_014099773.1), Z. cucurbitae PGRP-SB (XP_011181375.1), C. capitate PGRP-SB (XP_004537949.1), R. zephyria PGRP-SB (XP_017486043.1), R. pomonella PGRP-SB (XP_036336342.1), D. melanogaster PGRP-SB (CAD89135.1), M. domestica PGRP-SB (NP_001295929.1), and B. mori PGRP-SB (XP_004929843.1). (C) Multiple alignments of PGRP-SC $2 . B d P G R P-S C_{2}$ was aligned with B. latifrons PGRP-SC 2 (XP_018798904.1), B. oleae PGRP-SC 2 (XP_014085196.2), C. capitate PGRP-SC 2 (XP_004520319.1), Z. cucurbitae PGRP-SC 2 (XP_011180165.1), R. pomonella PGRP-SC 2 (XP_036334551.1), M. domestica PGRP-SC 2 (XP_005184140.3), D. melanogaster PGRP-SC 2 (CAD89184.1), A. aegypti PGRP-SC 2 (XP_011492940.1), and B. mori PGRP-SC 2 (XP_004929814.1). The identical amino acids are shown against a black background; $75 \%$ conserved amino acids are shown against a pink background; $50 \%$ conserved amino acids are shown against a blue background. The signal peptides are indicated by dashed lines. The amidase domains are indicated by solid lines. Black arrows indicate the amino acid residues required for the recognition of DAP-type peptidoglycan. Grey arrows indicate the amino acid residues required for $\mathrm{Zn}^{2+}$ binding. White arrows indicate the amino acid residues required for amidase activity.
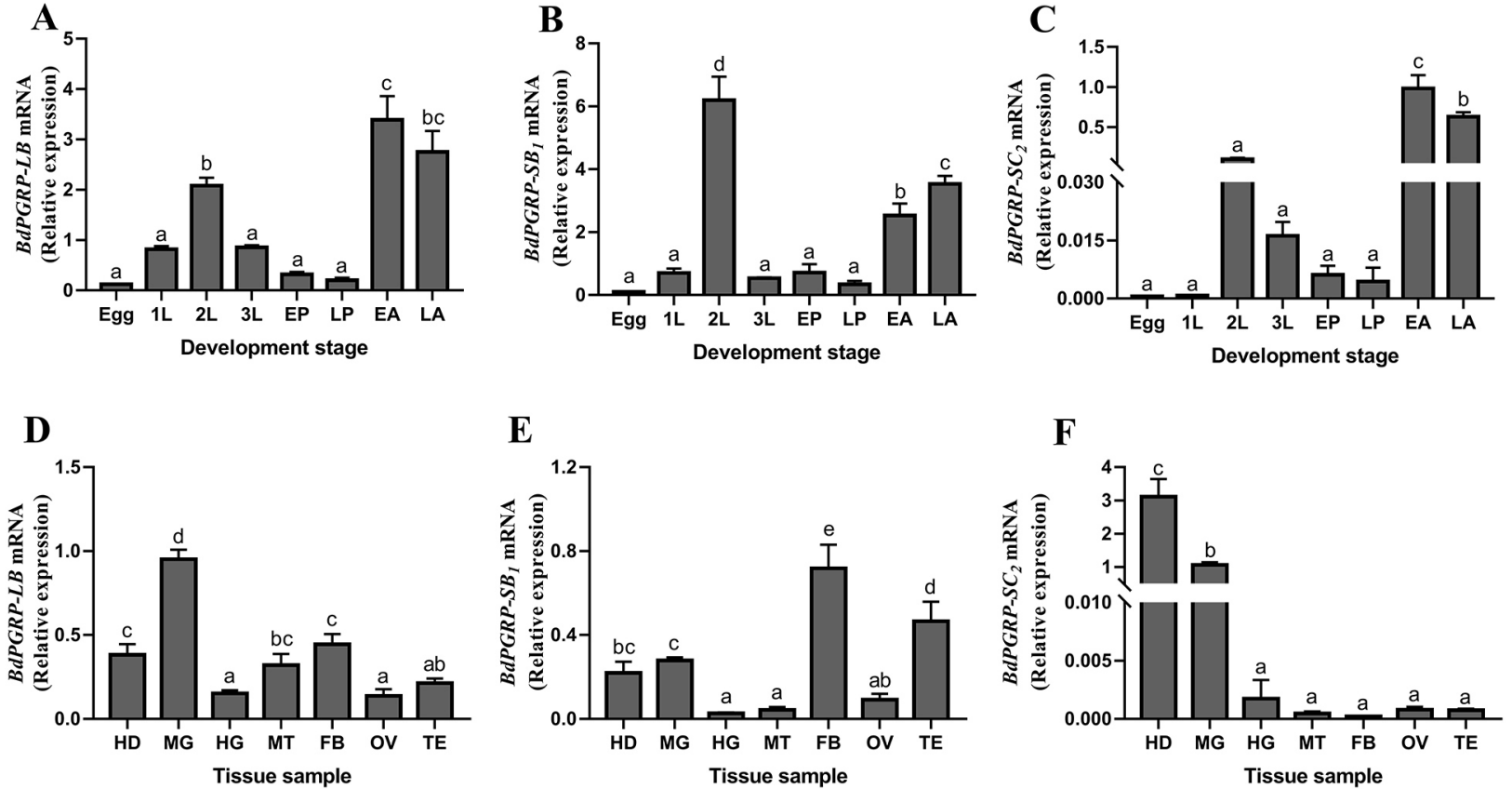

Figure 2. Expression profiles of BdPGRPs in B.dorsalis. (A) Relative expression of BdPGRP-LB at different development stages. (B) Relative expression of $B d P G R P-S B_{1}$ at different development stages.(C) Relative expression of $B d P G R P-S C_{2}$ at different development stages. (D) Relative expression of $B d P G R P-L B$ from different tissue samples. (E) Relative expression of $B d P G R P-S B_{1}$ from different tissue samples. (F) Relative expression of $B d P G R P-S C_{2}$ from different tissue samples. $B$. dorsalis was collected at various developmental stages: $1 \mathrm{~L}$, 1st instar larvae; $2 \mathrm{~L}, 2$ nd instar larvae; $3 \mathrm{~L}, 3 \mathrm{rd}$ instar larvae; EP, early pupal stage; LP, late pupal stage; EA, newly emergence adults; LA, late adult stage. Different adult tissues were collected: HD, head; MG, midgut; HG, hindgut; MT, Malpighian tube; $\mathrm{FB}$, fatbody; OV, ovary; TE, testis. Multiple comparisons were carried out with one-way analysis of 
variance (ANOVA) and Turkey's test in SPSS 16.0. Different lower-case letters indicate a significant difference at the level of $p<0.05$ and a confidence interval of $95 \%$. The relative gene expression data were analyzed using a $2^{-\Delta \Delta C T}$ method and the data were normalized to reference gene Rpl32.

\subsection{Responses of BdPGRPs to Systemic Bacterial Infection}

To investigate the $B d P G R P$ s response to bacterial challenge, the expression of $B d P G R P$ $L B, B d P G R P-S B_{1}$ and BdPGRP-SC 2 at $1 \mathrm{~h}, 3 \mathrm{~h}, 6 \mathrm{~h}, 9 \mathrm{~h}, 12 \mathrm{~h}, 24 \mathrm{~h}$ and $48 \mathrm{~h}$ after E. coli thorax inoculation was monitored in whole insects. The results showed that there was a significant increase of the expression of BdPGRP-LB and BdPGRP-SB 1 during 3-24h infection, with a 1.90-2.99-fold and 1.40-3.62-fold increase, respectively (Figure 3B,C). Unexpectedly, there was a decrease of $B d P G R P-S C_{2}$ at $9 \mathrm{~h}, 24 \mathrm{~h}$ and $48 \mathrm{~h}$ following inoculated with $E$. coli, and no response at other times post infection (Figure 3D). We also found an immune response of effector genes of the Imd pathway to $E$. coli infection; there was a 1.76-5.13-fold increase of the expression of the antimicrobial peptide gene Diptericin at $6 \mathrm{~h}-48 \mathrm{~h}$ post infection (Figure 3A). The relative expression of other antimicrobial peptide genes including AttacinA, AttacinB, AttacinC and Cecropin were also induced by E. coli infection, thus confirming the strong immunogenic nature of E. coli infection in B. dorsalis. (Supplementary Figure S3A-D). The above results indicate that inoculation with $E$. coli can immediately activate the immune response of the Imd pathway in $B$. dorsalis.
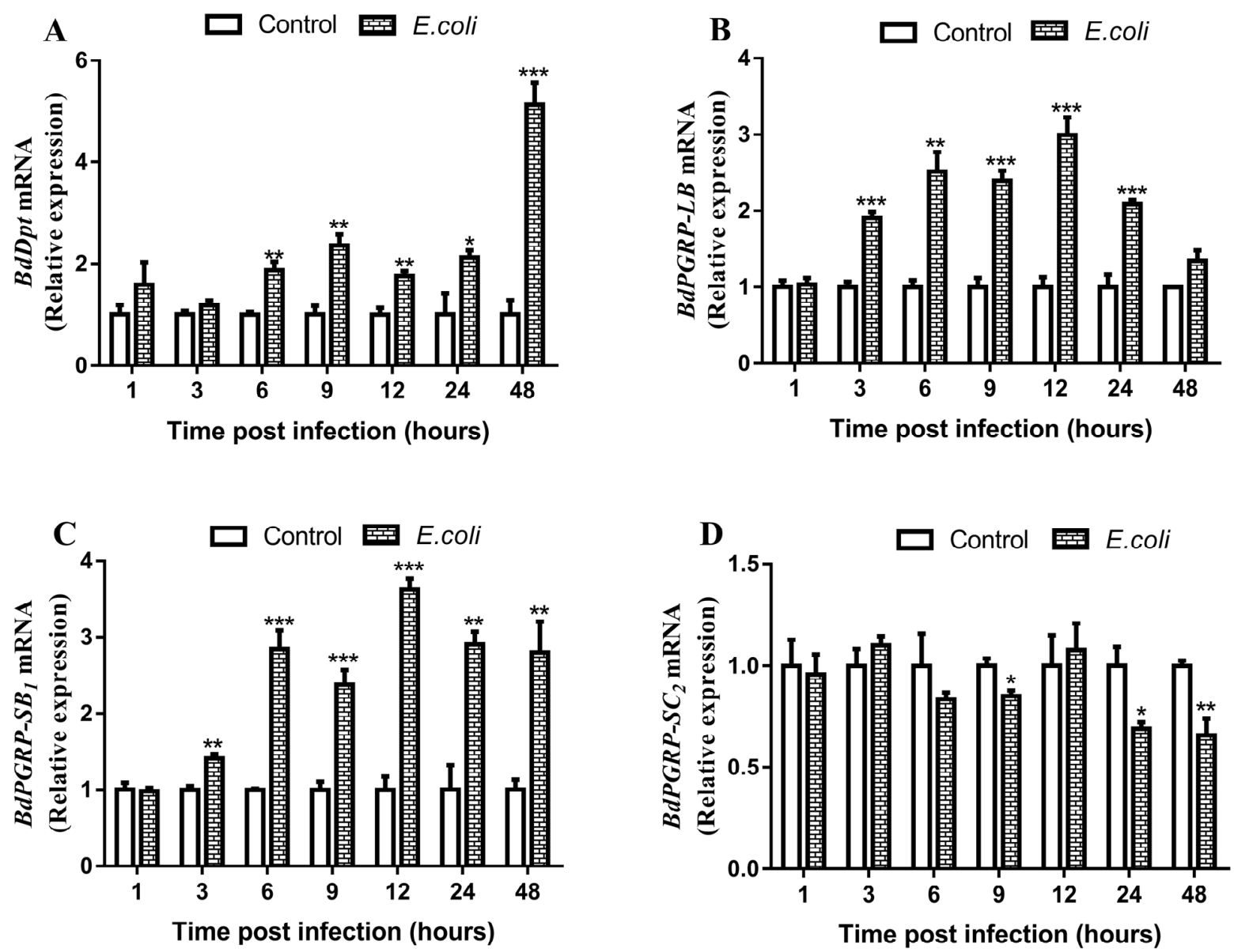

Figure 3. Responses of $D p t$ and $B d P G R P S$ to opportunistic pathogen E. coli challenges. Relative expression of $D p t(\mathbf{A}), B d P G R P-L B(\mathbf{B}), B d P G R P-S B_{1}(\mathbf{C})$, and $B d P G R P-S C_{2}(\mathbf{D})$ after infection with $E$. coli at different time points, respectively. The data are expressed as mean $\pm \mathrm{SEM}$ and the mean refers to the average of four biological replicates for each sample. Statistical analysis was based on Student's $t$-test. ${ }^{*} p<0.05 ;{ }^{* *} p<0.01 ;{ }^{* * *} p<0.001$. The relative gene expression data were analyzed using a $2^{-\Delta \Delta C T}$ method and the data were normalized to reference gene Rpl32. 


\subsection{RNA Interference (RNAi) of BdPGRPs}

Based on sequence similarity (Figure 1), numerous off-targets are predicted to occur in RNAi experiments [30]. To test whether potential off-target effects of $d s-P G R P s$ exist, the off-target effect was analysed by qRT-PCR (Figure 4). When BdPGRP-LB RNAi was performed, the relative expression of $B d P G R P-S B_{1}$ and $B d P G R P-S C_{2}$ was also detected one day after dsRNA injection. Results showed that the expression of $B d P G R P-S B_{1}$ and $B d P G R P-S C_{2}$ were not affected by $B d P G R P-L B$ knock down (Figure $4 \mathrm{~A}$ ). $B d P G R P-S B_{1}$ RNAi did not affect the relative expression of $B d P G R P-L B$ and $B d P G R P-S C_{2}$ (Figure $4 \mathrm{~B}$ ), nor did $B d P G R P-S C_{2}$ RNAi (Figure $4 \mathrm{C}$ ). These results suggested that there was no off-target effect in the $B d P G R P s$ knockdown experiment in $B$. dorsalis.
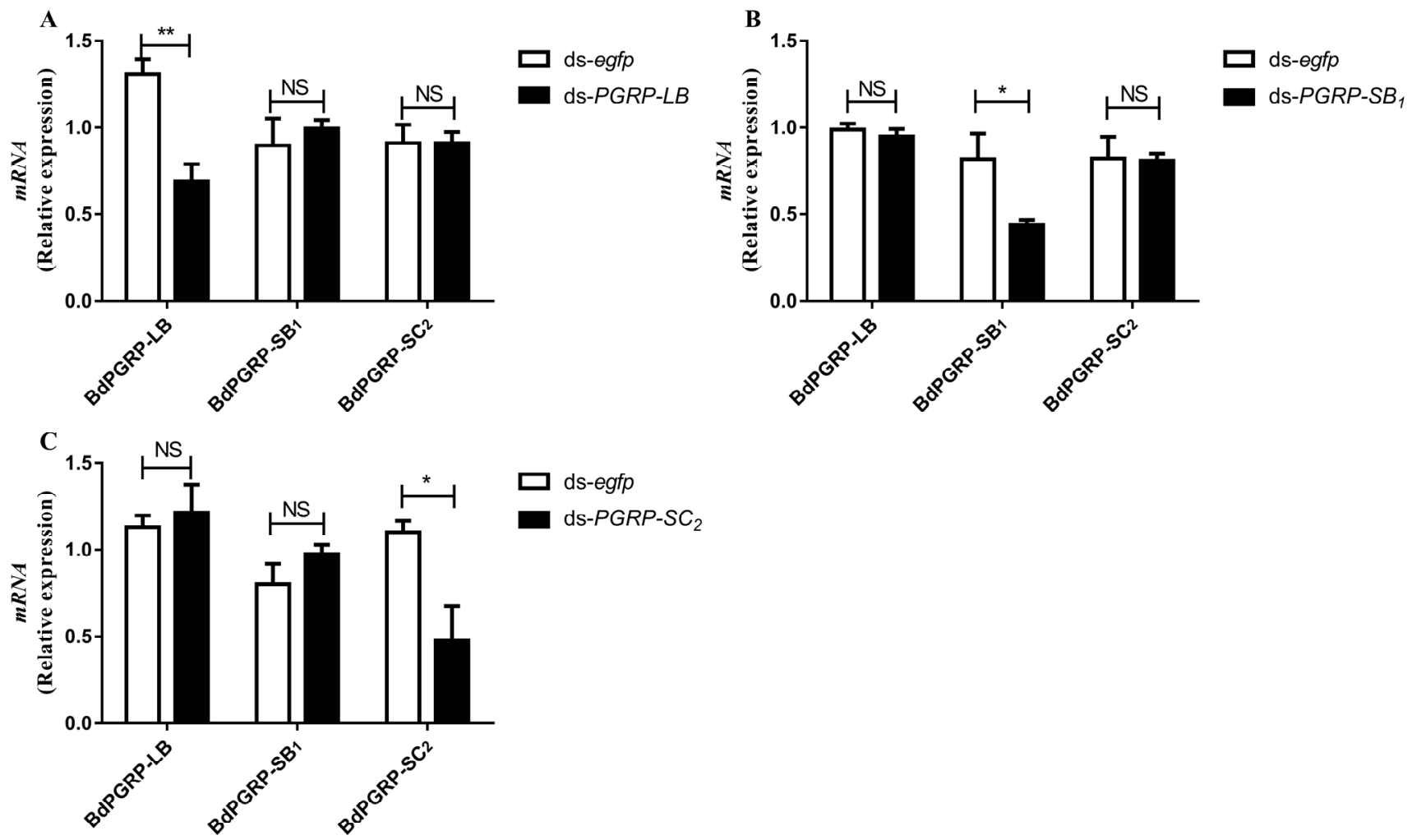

Figure 4. Off-target detection after dsRNA injection. (A) Influence of silencing $B d P G R P-L B$ on expression of $B d P G R P-S B_{1}$ and $B d P G R P-S C_{2}$. (B) Influence of silencing $B d P G R P-S B_{1}$ on expression of $B d P G R P-L B$ and $B d P G R P-S C_{2}$. (C) Influence of silencing $B d P G R P-S C_{2}$ on expression of $B d P G R P-L B$ and $B d P G R P-S B_{1}$. All error bars represent the SEM of the mean of three independent biological replicates. Statistical analysis was based on Student's $t$-test. ${ }^{*} p<0.05 ;{ }^{* *} p<0.01$; NS, no significant difference; $p>0.05$. The relative gene expression data were analyzed using a $2^{-\Delta \Delta C T}$ method and the data were normalized to reference gene Rpl32.

To evaluate the RNAi efficiency of $B d P G R P s$, we then monitored the expression of transcripts $B d P G R P-L B, B d P G R P-S B_{1}$ and $B d P G R P-S C_{2}$ in whole body samples at different days post-dsRNA injection (DPI). The results showed that the expression of $B d P G R P-L B$ was significantly reduced, by $75.3 \%, 81.4 \%$ and $66.9 \%$ in the $d s-B d P G R P-L B$ injection group at 1,3 and 5 DPI when compared to the control $d s$-egfp group (Figure $5 \mathrm{~A}$ ); the expression of $B d P G R P-S B_{1}$ was significantly reduced, by $87.4 \%, 88.2 \%$ and $93 \%$ in the $d s-B d P G R P-S B_{1}$ dsRNA injection group at 1, 3 and 5 DPI (Figure $5 \mathrm{~B}$ ); and the expression of $B d P G R P-S C_{2}$ was significantly reduced, by $33.7 \%, 28.5 \%$ and $39 \%$ in the $d s-B d P G R P-S C_{2}$ dsRNA injection group at 1, 3 and 5 DPI (Figure 5C). 
A

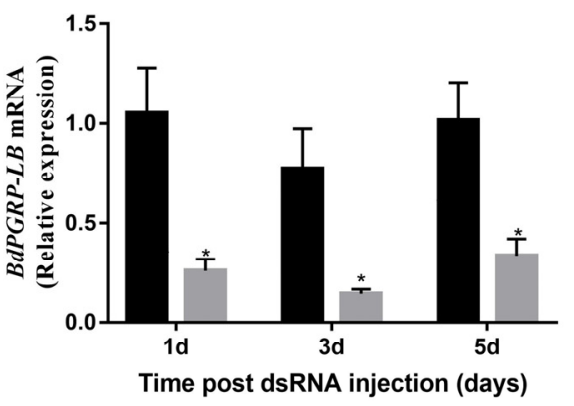

C

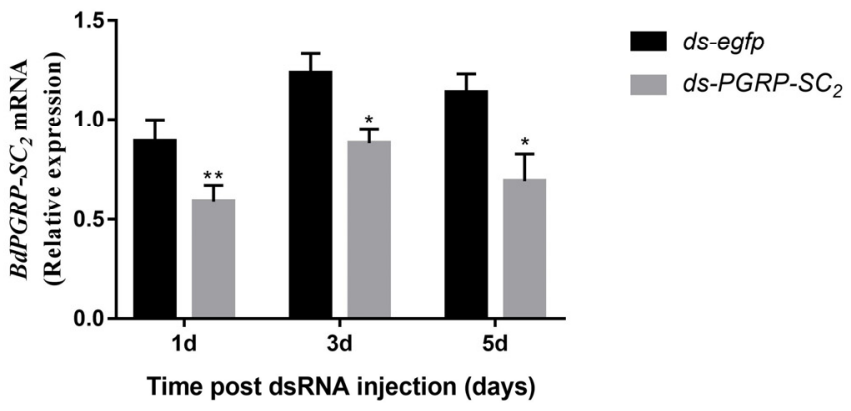

B

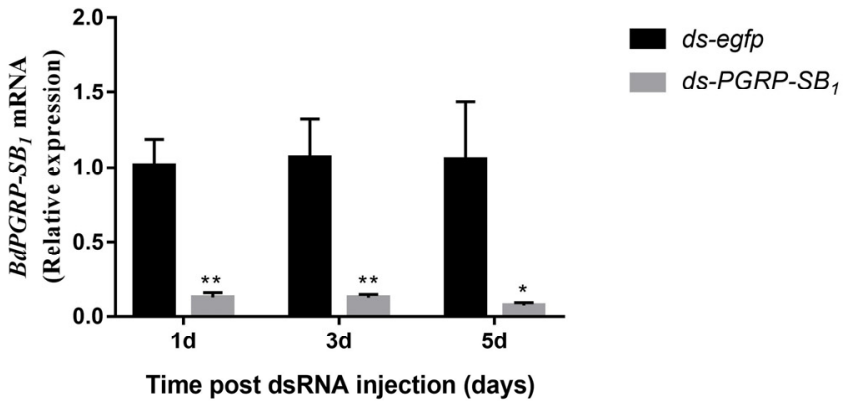

Figure 5. RNA interference efficiency of $B d P G R P s$. Relative expression of $P G R P-L B$ (A), $P G R P-S B_{1}$ (B), and $P G R P-S C_{2}$ (C) after dsRNA injection at different time points with whole body samples. All error bars represent the SEM of the mean of three independent biological replicates. Statistical analysis was based on Student's $t$-test. ${ }^{*} p<0.05 ;{ }^{* *} p<0.01$. The relative gene expression data were analyzed using a $2^{-\Delta \Delta C T}$ method and the data were normalized to reference gene Rpl32.

\subsection{The Negative Regulatory Roles of BdPGRPs in Imd Pathway}

To analyze the potential roles of $B d P G R P-L B, B d P G R P-S B_{1}$ and $B d P G R P-S C_{2}$ in the Imd pathway of $B$. dorsalis, we infected ds-egfp, ds-BdPGRP-LB, $d s-B d P G R P-S B_{1}$ and $d s-$ $B d P G R P-S C_{2}$ treated flies with E. coli and measured $D p t$ transcript levels as a readout for Imd pathway activation. At $24 \mathrm{~h}$ and $48 \mathrm{~h}$ post $E$. coli infection, there was a 1.5 and 1.92 -fold enhanced expression of $D p t$ in the infected $d s-B d P G R P-L B$ group, respectively, compared to the infected $d s$-egfp group (Figure 6A). There was a 1.43-2.3-fold increase in expression of $D p t$ in the infected $d s-B d P G R P-S B_{1}$ group compared to the infected $d s$-egfp group at 6 , 12,24 and $48 \mathrm{~h}$ post $E$. coli infection (Figure $6 \mathrm{~B}$ ). The knockdown of $B d P G R P-S C_{2}$ led to a $1.74,1.62$ and 1.49-fold enhanced expression of $D p t$ at 6, 12 and 24 h post $E$. coli infection, respectively, as compared with infected $d s-e g f p$ group (Figure $6 \mathrm{~B}$ ). These results indicate that silencing of either $B d P G R P-L B, B d P G R P-S B$ or $B d P G R P-S C_{2}$ will induce overactivation of the Imd pathway upon bacterial infection, as all these three BdPGRPs perform negative regulatory roles in regulating $A M P$ s gene expression in the Imd pathway of $B$. dorsalis. 
A
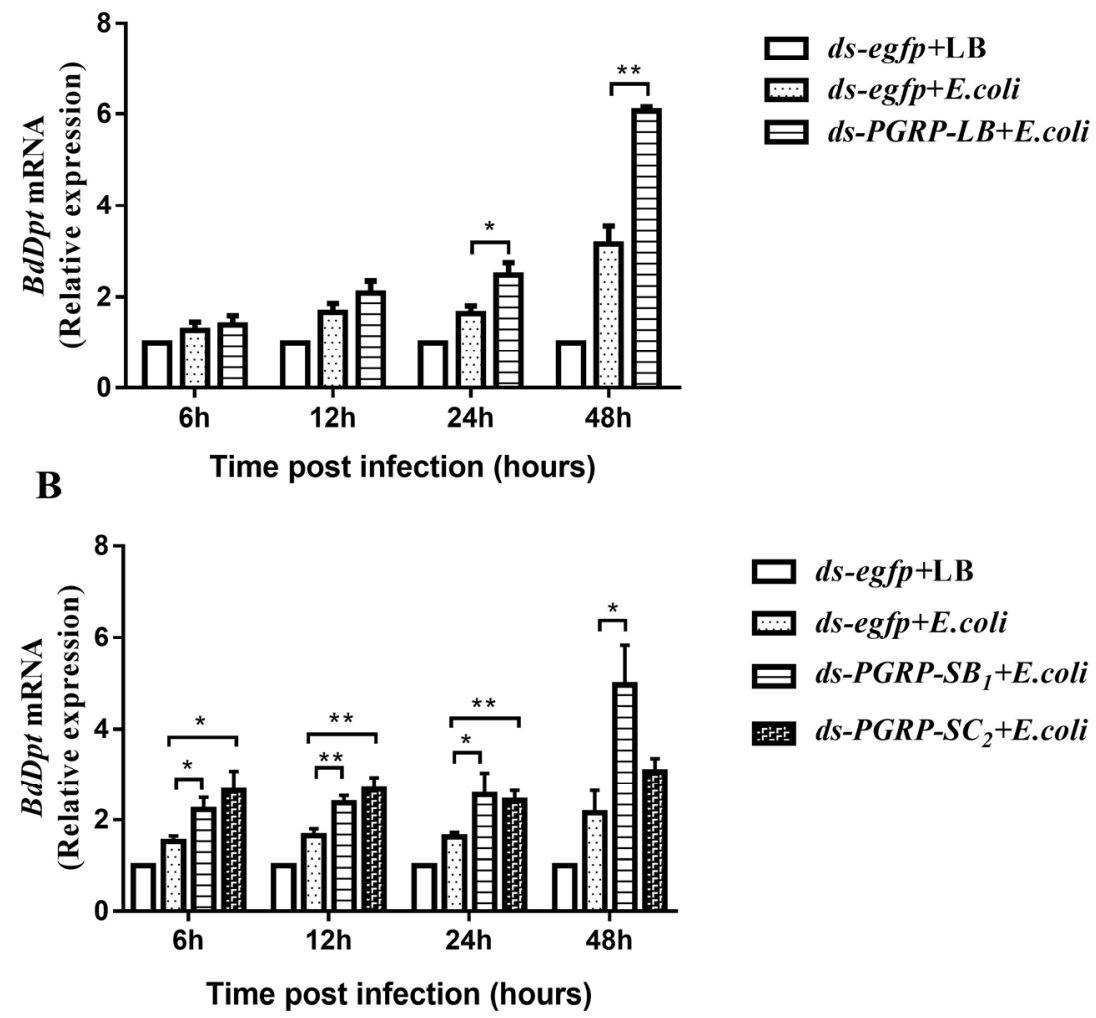

$\square d s-e g f p+\mathrm{LB}$

ds-egfp+E.coli

E ds-PGRP-SB + E.coli

GEFE $d s-P G R P-S C_{2}+E . c o l i$

Figure 6. Antimicrobial peptide gene expression in BdPGRPs RNAi flies after bacterial challenges. $(\mathbf{A}, \mathbf{B})$ Injury infection with E. coli induced a higher Diptericin (Dpt) expression in BdPGRPS RNAi flies than in the ds-egfp dsRNA injection flies. The data are expressed as the mean $\pm \mathrm{SEM}$, and the mean refers to the average of at least three replicates for each sample. Statistical analysis was based on Student's $t$-test. ${ }^{*} p<0.05 ;{ }^{* *} p<0.01$. The relative gene expression data were analyzed using a $2^{-\triangle \Delta C T}$ method and the data were normalized to reference gene Rpl32.

\subsection{BdPGRPs RNAi Decreased Flies Survival Rate after Bacterial Challenge}

After $24 \mathrm{~h}$ post dsRNA injection, flies that were alive in the control and treatment groups were individually challenged with E. coli by inoculation with bacteria in the thorax. From the results, we observed that the survival rate of infected flies was significantly lower than in the control group (Figure 7A). However, when BdPGRP-LB, BdPGRP-SB 1 and $B d P G R P-S C_{2}$ were silenced individually this did not affect survival status when compared with $d s-e g f p$ flies upon bacterial challenge (Figure 7A). Considering the functional redundancy of BdPGRPs in $B$. dorsalis, we knocked down of all three BdPGRPs. The results showed that the survival rate of the $d s-B d P G R P s$ group was significantly reduced compared with the $d s-e g f p$ group after E. coli infection (Figure 7B). The median survival of $d s-e g f p$ group was nine days, while in the $d s-B d P G R P s$ group it was shortened to three days. 


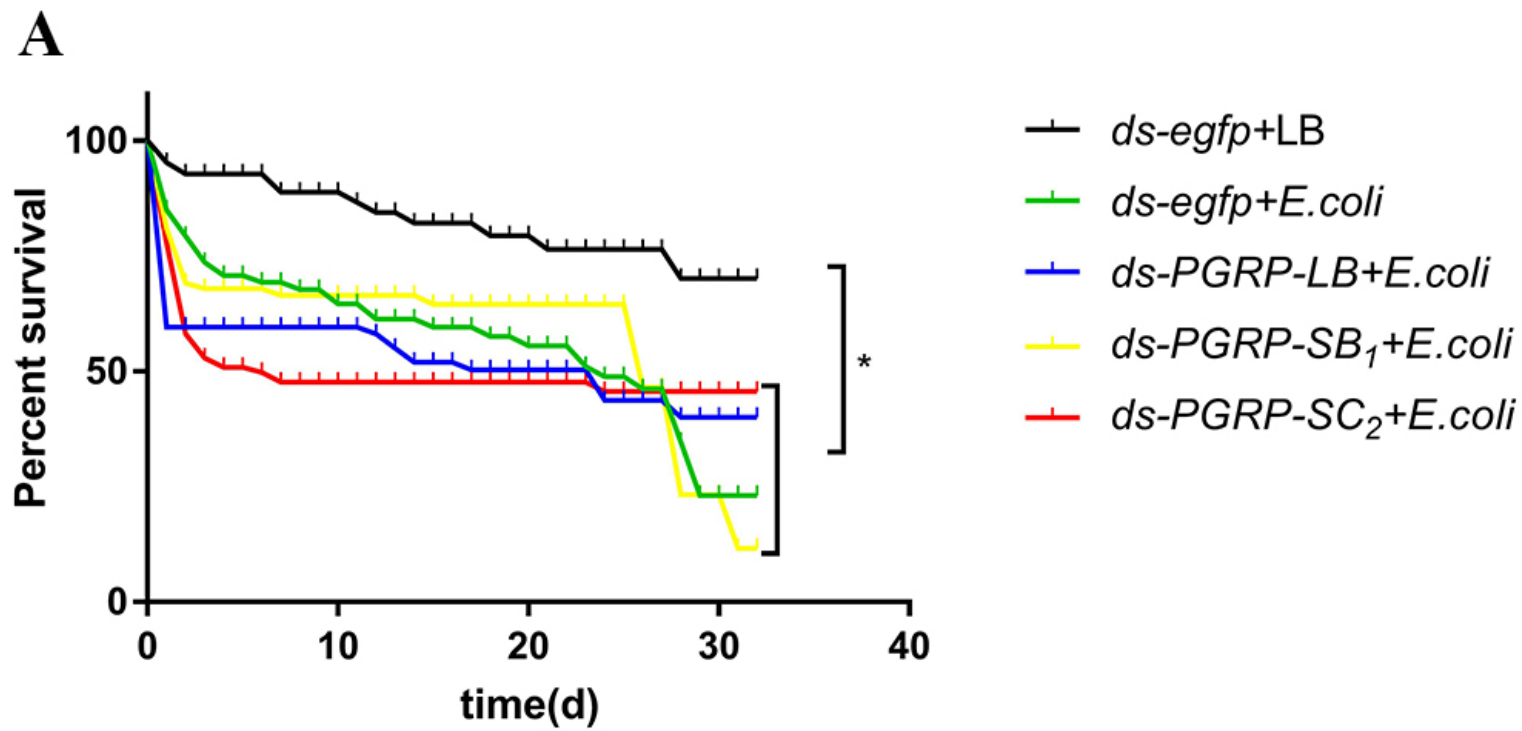

B

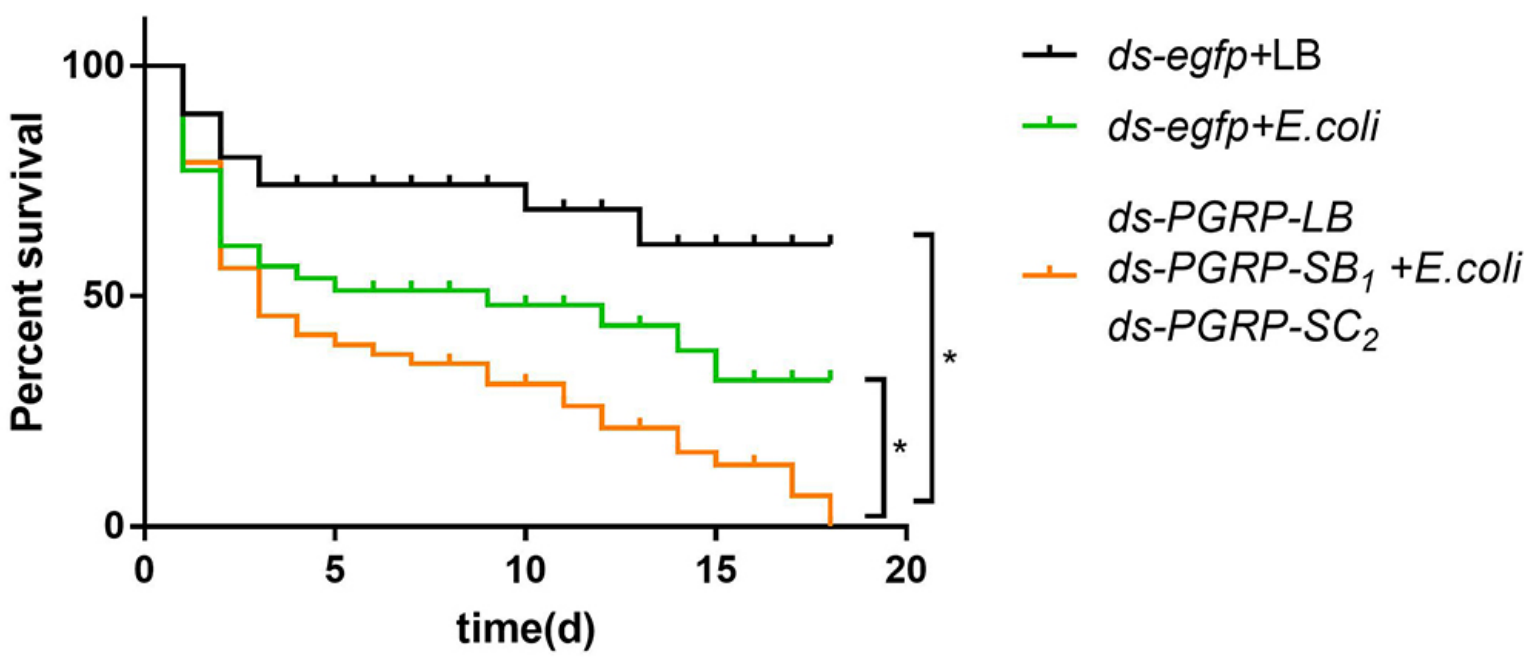

Figure 7. Survival rate of B. dorsalis after BdPGRPS RNAi followed by E. coli infection. (A) Three BdPGRPs were knocked down separately. (B) Three BdPGRPs were knocked down the same time. Statistical analysis was based on Log-rank (Mantel-Cox) test $\left({ }^{*} p<0.05\right)$.

\section{Discussion}

The PGRP family has been thoroughly studied in the last decade. PGRPs are evolutionally conserved proteins involved in the recognition and degradation of peptidoglycans, a cell wall component of bacteria [34]. PGRPs are involved in many immune processes ranging from initiation to termination of host immune activity; however, most research work has been concentrated in model animals such as in mice and Drosophila [12,23,35-37]. Here, we have characterized the immunological role of three PGRP family genes, $B d P G R P$ $L B, B d P G R P-S B_{1}$ and $B d P G R P-S C_{2}$, after inoculation with the Gram-negative bacterium $E$. coli in $B$. dorsalis. After applying RNAi methods to knock down BdPGRPs followed by Gram-negative bacterial infection, $D p t$, a marker of IMD pathway activation, showed a significant increase compared with the $d s$-egfp group. The survival rate of the $d s-B d P G R P s$ group was significantly reduced compared to the $d s-e g f p$ group after $E$. coli infection. Our results showed that $B d P G R P-L B, B d P G R P-S B_{1}$ and $B d P G R P-S C_{2}$ performed vital negative roles in regulating expression of $A M P s$ in the Imd pathway of $B$. dorsalis, and maintaining 
the normal function of these three $B d P G R P S$ is critical to host health when faced with bacterial challenge.

In this study, the results of the protein prediction indicated that BdPGRP-LB, BdPGRP$S B_{1}$ and $B d P G R P-S C_{2}$ all have type 2 amidase domains, which suggests that $B d P G R P-L B$, $B d P G R P-S B_{1}$ and $B d P G R P-S C_{2}$ have amidase activity. PGRPs which have type 2 amidase domains have been confirmed to have important roles in innate immunity, not only in the model specie Drosophila [10] but in other insects such as Tenebrio Molitor [38], Anopheles gambiae [39], and Nilaparvata lugens [40]. This may indicate that the structure and function of PGRPs is highly conserved. All amidase-active PGRPs have a conserved $\mathrm{Zn}^{2+}$-binding site in the peptidoglycan-binding groove, which is also present in bacteriophage type 2 amidases and consists of two histidines, one tyrosine, and one cysteine [10]. The results on expression patterns showed that $B d P G R P-L B$ and $B d P G R P-S C_{2}$ were very highly expressed in the midgut of adults, while the $B d P G R P-S B_{1}$ gene was mainly expressed in the fat body. The tissue expression profiling of BdPGRPs is similar with previous reports in other insects $[8,10,26,41]$. The fat body is the major tissue that generates AMPs to hemolymph in the systemic immune system, and intestinal epithelial cells produce AMPs to inhibit the overgrowth of pathogenic bacteria in gut lumen [6]. In the fat body of insects, characterized immune genes are induced by microbial infection and encode antimicrobial peptides which are then released into the hemolymph to defeat invading pathogens [42]. Updated research reveals that fat body tissues also synthesize and secrete some TEP and TOP peptides, which aid hemocyte phagocytosis [43]. Insects gut continually come in contact with microbiota, which generates a delicate intestinal immune response which must tolerate the presence of gut microbiota and dietary microorganisms while responding to and eliminating potential pathogens [13]. BdPGRP-LB, BdPGRP-SB 1 and $B d P G R P-S C_{2}$ all have highly conserved type 2 amidase domains and are highly expressed in immunocompetent tissues in $B$. dorsalis, indicating that BdPGRPs probably participate in the immune response of $B$. dorsalis, as in other insects.

In our study, injury infection with Gram-negative bacteria E. coli induced significantly higher transcript levels of $B d P G R P-L B$ and $B d P G R P-S B_{1}$ simultaneously. A similar immune expression of PGRP-LB has also been observed in Drosophila, where the expression of PGRP$L B$ was increased significantly following septic injury with E. carotovora [44]. $P G R P-S B_{1}$ is strongly induced with injection of bacteria containing DAP-type PGN, which activates the Imd pathway [16]. Unexpectedly, there was a dramatic decrease in $B d P G R P-S C_{2}$ expression upon systemic infection with E. coli. Similar results were observed in Musca domestica larvae; MdPGRP-SC cannot be induced when challenged by E. coli or S. aureus [26]. Based on the high expression of PGRP-SC in the guts of other insects [8,26], it is possible that PGRP-SC exerts its immune function in the gut. Stress stimulation can induce the transcription factor Foxo to help the host adapt to an adverse situation [45]. Guo et al. (2014) showed that chronic activation of the transcription factor Foxo reduces expression of $P G R P-S C_{2}$ in Drosophila [15]. Therefore, it is plausible that the injury infection may induce the expression of $B d F o x_{0}$, then decrease the expression of $B d P G R P-S C_{2}$; however, further experiments are needed to reveal this phenomenon and its underlying mechanism. The knockdown of any $B d P G R P-L B, B d P G R P-S B_{1}$ and $B d P G R P-S C_{2}$ in flies will result in overactivation of the Imd signaling pathway upon bacterial challenge. The roles of $B d P G R P-L B$ and $B d P G R P-S C_{2}$ in $B$. dorsalis were consistent with previous findings in D. melanogaster that $P G R P-L B$ and $P G R P-S C_{2}$ act as important negative regulators of the Imd pathway $[13,44,46,47]$. After septic injury with the Gram-negative bacterium Erwinia carotovora carotovora 15 (Ecc15), PGRP-LB deletion mutant flies had stronger and more sustained immune response than wild-type flies as measured by the expression of the antibacterial peptide gene Diptericin $(D p t)$, a readout of the Imd pathway. In contrast with the Zaidman-Rémy et al. (2011) report in D. melanogaster that injection of Gram-negative bacteria Ecc15 did not affect the AMPs expression in PGRP-SB null mutant [16], the silencing of BdPGRP-SB 1 in B. dorsalis induced enhanced expression of $D p t$ compared with the $d s-e g f p$ group after bacterial challenge. The discordance may be caused by different insect species having distinct catalytic PGRPs to 
regulate their systemic immune response. In Drosophila, three isoforms of PGRP-LB have two distinct functions; the PGRP-LB ${ }^{\mathrm{PC}}$ isoform is required to control the systemic response in the fat body, while PGRP-LB ${ }^{\mathrm{PA}}$ and PGRP-LB ${ }^{\mathrm{PD}}$ isoforms show the immune function only in gut [48]. In our results, we found that each of the three BdPGRPs performed its individual negative function in the systemic Imd pathway of $B$. dorsalis, because the immune phenotype caused by the absence of one of the three BdPGRPs cannot be compensated by the other two. Collectively, our results showed that these three PGRP family genes act as negative regulators in the systemic immune response of $B$. dorsalis by dampening the activation of the Imd pathway.

A tight balance between initiation and resolution in the control of inflammation is very important in animals, as both the absence and overactivity of immune response are harmful to the host [46]. Our results showed that the survival rate of the $d s-B d P G R P s$ group was significant reduced compared with the $d s-e g f p$ group. However, the death events were mostly observed shortly after infection and mid-to-late post-infection. Death in the short term may be caused by an overreaction of the immune system [13], while death in the middle and late stages may be caused by excessive energy consumption in response to infection [49]. Noncatalytic PGRPs are crucial for the sensing of bacteria in insects such as in Drosophila, and catalytic PGRPs play a vital role in hydrolyzing peptidoglycan by cleaving the amide bond [13]. The bacterial infection induced the expression of PGRP-LB, PGRP-SB and $P G R P-S C_{2}$ to degrade PGN and repress the activation of $P G R P-L C$, which reportedly is the major receptor of the Imd pathway [22], in order to ensure that the immune response is at an appropriate level. This negative regulation integrates into the sensitive immune regulation mechanism of insects, which keeps pathogenic bacteria below the level where they can cause harm and ensures that the host will not be harmed by an overactive immune response.

Supplementary Materials: The following supporting information can be downloaded at: https: / / www.mdpi.com/article/10.3390/cells11010152/s1, Figure S1: Prediction of BdPGRPs' functional domains; Figure S2: Phylogenetic tree of peptidoglycan recognition proteins of $B$. dorsalis and other insects; Figure S3: Expression levels of AMPs in Imd pathway after E. coli challenge; Table S1: Primers used in supplementary experiments.

Author Contributions: H.Z., P.Z. and Z.Y. conceived and designed the project. P.Z., Z.Y. and S.B. performed experiments, and Z.Y. analysed data. Z.Y. and P.Z. made the graphs. P.Z. and S.B. reared the flies. H.Z., P.Z. and Z.Y. wrote the manuscript. All authors have read and agreed to the published version of the manuscript.

Funding: This work was supported by the National Natural Science Foundation of China (Nos. 31872931, 31572008 and 31801744), China Agriculture Research System of MOF and MARA (No. CARS-26).

Institutional Review Board Statement: Not applicable.

Informed Consent Statement: Not applicable.

Data Availability Statement: The data presented in this study are available within this artivle.

Conflicts of Interest: The authors declare no conflict of interest.

\section{References}

1. Tzou, P.; De Gregorio, E.; Lemaitre, B. How Drosophila combats microbial infection: A model to study innate immunity and host-pathogen interactions. Curr. Opin. Microbiol. 2002, 5, 102-110. [CrossRef]

2. Janeway, C.; Medzhitov, R. Innate immune recognition. Annu. Rev. Immunol. 2002, 20, 197-216. [CrossRef]

3. Guan, R.; Mariuzza, R.A. Peptidoglycan recognition proteins of the innate immune system. Trends Microbiol. 2007, 15, 127-134. [CrossRef]

4. Royet, J.; Dziarski, R. Peptidoglycan recognition proteins: Pleiotropic sensors and effectors of antimicrobial defences. Nat. Rev. Microbiol. 2007, 5, 264-277. [CrossRef] [PubMed]

5. Mengin-Lecreulx, D.; Lemaitre, B. Structure and metabolism of peptidoglycan and molecular requirements allowing its detection by the Drosophila innate immune system. J. Endotoxin Res. 2005, 11, 105-111. [CrossRef] 
6. Lemaitre, B.; Hoffmann, J. The Host Defense of Drosophila melanogaster. Annu. Rev. Immunol. 2007, 25, 697-743. [CrossRef] [PubMed]

7. Yoshida, H.; Kinoshita, K.; Ashida, M. Purification of a peptidoglycan recognition protein from hemolymph of the silkworm, Bombyx mori. J. Biol. Chem. 1996, 271, 13854-13860. [CrossRef] [PubMed]

8. Werner, T.; Liu, G.; Kang, D.; Ekengren, S.; Steiner, H.; Hultmark, D. A family of peptidoglycan recognition proteins in the fruit fly Drosophila melanogaster. Proc. Natl. Acad. Sci. USA 2000, 97, 13772-13777. [CrossRef] [PubMed]

9. Christophides, G.; Zdobnov, E.; Barillas-Mury, C.; Birney, E.; Blandin, S.; Blass, C.; Brey, P.; Collins, F.; Danielli, A.; Dimopoulos, G.; et al. Immunity-related genes and gene families in Anopheles gambiae. Science 2002, 298, 159-165. [CrossRef] [PubMed]

10. Dziarski, R.; Gupta, D. The peptidoglycan recognition proteins (PGRPs). Genome Biol. 2006, 7, 232. [CrossRef]

11. Wang, S.; Beerntsen, B.T. Insights into the different functions of multiple peptidoglycan recognition proteins in the immune response against bacteria in the mosquito, Armigeres subalbatus. Insect Biochem. Mol. Biol. 2013, 43, 533-543. [CrossRef] [PubMed]

12. Buchon, N.; Broderick, N.A.; Lemaitre, B. Gut homeostasis in a microbial world: Insights from Drosophila melanogaster. Nat. Rev. Microbiol. 2013, 11, 615-626. [CrossRef] [PubMed]

13. Paredes, J.C.; Welchman, D.P.; Poidevin, M.; Lemaitre, B. Negative Regulation by Amidase PGRPs Shapes the Drosophila Antibacterial Response and Protects the Fly from Innocuous Infection. Immunity. 2011, 35, 770-779. [CrossRef]

14. Mellroth, P.; Karlsson, J.; Steiner, H. A scavenger function for a Drosophila peptidoglycan recognition protein. J. Biol. Chem. 2003, 278, 7059-7064. [CrossRef] [PubMed]

15. Guo, L.; Karpac, J.; Tran, S.L.; Jasper, H. PGRP-SC2 Promotes Gut Immune Homeostasis to Limit Commensal Dysbiosis and Extend Lifespan. Cell 2014, 156, 109-122. [CrossRef]

16. Zaidman-Rémy, A.; Poidevin, M.; Hervé, M.; Welchman, D.P.; Paredes, J.C.; Fahlander, C.; Steiner, H.; Mengin-Lecreulx, D.; Lemaitre, B. Drosophila Immunity: Analysis of PGRP-SB1 Expression, Enzymatic Activity and Function. PLoS ONE 2011, 6, e17231. [CrossRef] [PubMed]

17. Li, X.; Zhang, M.; Zhang, H. RNA interference of four genes in adult Bactrocera dorsalis by feeding their dsRNAs. PLoS ONE 2011, 6, e17788. [CrossRef]

18. Clarke, A.R.; Armstrong, K.F.; Carmichael, A.E.; Milne, J.R.; Raghu, S.; Roderick, G.K.; Yeates, D.K. Invasive phytophagous pests arising through a recent tropical evolutionary radiation: The Bactrocera dorsalis Complex of Fruit Flies. Annu. Rev. Entomol. 2005, 50, 293-319. [CrossRef]

19. Li, Q.; Dong, X.; Zheng, W.; Zhang, H. The PLA2 gene mediates the humoral immune responses in Bactrocera dorsalis (Hendel) Dev. Comp. Immunol. 2017, 67, 293-299. [CrossRef]

20. Dong, X.; Li, Q.; Zhang, H. The noa gene is functionally linked to the activation of the Toll/Imd signaling pathways in Bactrocera dorsalis (Hendel). Dev. Comp. Immunol. 2016, 55, 233-240. [CrossRef]

21. Yao, Z.; Wang, A.; Li, Y.; Cai, Z.; Lemaitre, B.; Zhang, H. The dual oxidase gene BdDuox regulates the intestinal bacterial community homeostasis of Bactrocera dorsalis. ISME J. 2016, 10, 1037-1050. [CrossRef]

22. Gottar, M.; Gobert, V.; Michel, T.; Belvin, M.; Duyk, G.; Hoffmann, J.; Ferrandon, D.; Royet, J. The Drosophila immune response against Gram-negative bacteria is mediated by a peptidoglycan recognition protein. Nature 2002, 416, 640-644. [CrossRef]

23. Bischoff, V.; Vignal, C.; Boneca, I.G.; Michel, T.; Hoffmann, J.A.; Royet, J. Function of the Drosophila pattern-recognition receptor PGRP-SD in the detection of Gram-positive bacteria. Nat. Immunol. 2004, 5, 1175-1180. [CrossRef] [PubMed]

24. Kaneko, T.; Yano, T.; Aggarwal, K.; Lim, J.H.; Ueda, K.; Oshima, Y.; Peach, C.; Erturk-Hasdemir, D.; Goldman, W.E.; Oh, B.H.; et al. PGRP-LC and PGRP-LE have essential yet distinct functions in the Drosophila immune response to monomeric DAP-type peptidoglycan. Nat. Immunol. 2006, 7, 715-723. [CrossRef] [PubMed]

25. Kurata, S. Extracellular and intracellular pathogen recognition by Drosophila PGRP-LE and PGRP-LC. Int. Immunol. 2010, 22, 143-148. [CrossRef] [PubMed]

26. Gao, Y.; Tang, T.; Gu, J.; Sun, L.; Gao, X.; Ma, X.; Wang, X.; Liu, F.; Wang, J. Downregulation of the Musca domestica peptidoglycan recognition protein SC (PGRP-SC) leads to overexpression of antimicrobial peptides and tardy pupation. Mol. Immunol. 2015, 67, 465-474. [CrossRef]

27. Dawadi, B.; Wang, X.; Xiao, R.; Muhammad, A.; Hou, Y.; Shi, Z. PGRP-LB homolog acts as a negative modulator of immunity in maintaining the gut-microbe symbiosis of red palm weevil, Rhynchophorus ferrugineus Olivier. Dev. Comp. Immunol. 2018, 86, 65-77. [CrossRef]

28. Maire, J.; Vincent-Monégat, C.; Balmand, S.; Vallier, A.; Hervé, M.; Masson, F.; Parisot, N.; Vigneron, A.; Anselme, C.; Perrin, J.; et al. Weevil pgrp-lb prevents endosymbiont TCT dissemination and chronic host systemic immune activation. Proc. Natl. Acad. Sci. USA 2019, 116, 5623-5632. [CrossRef] [PubMed]

29. Leulier, F.; Parquet, C.; Pili-Floury, S.; Ryu, J.; Caroff, M.; Lee, W.; Mengin-Lecreulx, D.; Lemaitre, B. The Drosophila immune system detects bacteria through specific peptidoglycan recognition. Nat. Immunol. 2003, 4, 478-484. [CrossRef]

30. Seinen, E.; Burgerhof, J.G.M.; Jansen, R.C.; Sibon, O.C.M. RNAi-induced off-target effects in Drosophila melanogaster: Frequencies and solutions. Brief. Funct. Genom. 2011, 10, 206-214. [CrossRef]

31. Livak, K.J.; Schmittgen, T.D. Analysis of relative gene expression data using real-time quantitative PCR and the 2(-Delta Delta C(T)) Method. Methods 2001, 25, 402-408. [CrossRef] 
32. Lim, J.H.; Kim, M.S.; Kim, H.E.; Yano, T.; Oshima, Y.; Aggarwal, K.; Goldman, W.E.; Silverman, N.; Kurata, S.; Oh, B.H. Structural Basis for Preferential Recognition of Diaminopimelic Acid-type Peptidoglycan by a Subset of Peptidoglycan Recognition Proteins. J. Biol. Chem. 2006, 281, 8286-8295. [CrossRef]

33. Beyenbach, K.; Skaer, H.; Dow, J. The developmental, molecular, and transport biology of Malpighian tubules. Annu. Rev. Entomol. 2010, 55, 351-374. [CrossRef]

34. Kurata, S. Recognition of infectious non-self and activation of immune responses by peptidoglycan recognition protein (PGRP)family members in Drosophila. Dev. Comp. Immunol. 2004, 28, 89-95. [CrossRef]

35. Ferrandon, D.; Imler, J.; Hetru, C.; Hoffmann, J. The Drosophila systemic immune response: Sensing and signalling during bacterial and fungal infections. Nat. Rev. Immunol. 2007, 7, 862-874. [CrossRef] [PubMed]

36. Saha, S.; Qi, J.; Wang, S.; Wang, M.; Li, X.; Kim, Y.G.; Núñez, G.; Gupta, D.; Dziarski, R. PGLYRP-2 and Nod2 are both required for peptidoglycan-induced arthritis and local inflammation. Cell Host Microbe 2009, 5, 137-150. [CrossRef] [PubMed]

37. Bosco-Drayon, V.; Poidevin, M.; Boneca, I.G.; Narbonne-Reveau, K.; Royet, J.; Charroux, B. Peptidoglycan Sensing by the Receptor PGRP-LE in the Drosophila Gut Induces Immune Responses to Infectious Bacteria and Tolerance to Microbiota. Cell Host Microbe 2012, 12, 153-165. [CrossRef]

38. Tindwa, H.; Patnaik, B.B.; Kim, D.H.; Mun, S.; Jo, Y.H.; Lee, B.L.; Lee, Y.S.; Kim, N.J.; Han, Y.S. Cloning, characterization and effect of TmPGRP-LE gene silencing on survival of Tenebrio molitor against Listeria monocytogenes infection. Int. J. Mol. Sci. 2013, 14, 22462-22482. [CrossRef]

39. Mendes, C.; Felix, R.; Sousa, A.M.; Lamego, J.; Charlwood, D.; do Rosário, V.E.; Pinto, J.; Silveira, H. Molecular evolution of the three short PGRPs of the malaria vectors Anopheles gambiae and Anopheles arabiensis in East Africa. BMC Evol. Biol. 2010, 10, 9 [CrossRef] [PubMed]

40. Bao, Y.Y.; Qu, L.Y.; Zhao, D.; Chen, L.B.; Jin, H.Y.; Xu, L.M.; Cheng, J.A.; Zhang, C.X. The genome- and transcriptome-wide analysis of innate immunity in the brown planthopper, Nilaparvata lugens. BMC Genom. 2013, 14, 160. [CrossRef]

41. Wang, J.; Aksoy, S. PGRP-LB is a maternally transmitted immune milk protein that influences symbiosis and parasitism in tsetse's offspring. Proc. Natl. Acad. Sci. USA 2012, 109, 10552-10557. [CrossRef]

42. Tsakas, S.; Marmaras, V.J. Insect immunity and its signalling: An overview. Invertebr. Surviv. J. 2010, 7, $228-238$.

43. Li, S.; Yu, X.; Feng, Q. Fat Body Biology in the Last Decade. Annu. Rev. Entomol. 2019, 64, 315-333. [CrossRef] [PubMed]

44. Zaidman-Rémy, A.; Hervé, M.; Poidevin, M.; Pili-Floury, S.; Kim, M.-S.; Blanot, D.; Oh, B.-H.; Ueda, R.; Mengin-Lecreulx, D.; Lemaitre, B. The Drosophila Amidase PGRP-LB Modulates the Immune Response to Bacterial Infection. Immunity 2006, 24, 463-473. [CrossRef] [PubMed]

45. Eijkelenboom, A.; Burgering, B.M. FOXOs: Signalling integrators for homeostasis maintenance. Nature Reviews Molecular Cell Biology 2013, 14, 83-97. [CrossRef] [PubMed]

46. Schneider, D.; Bischoff, V.; Vignal, C.; Duvic, B.; Boneca, I.G.; Hoffmann, J.A.; Royet, J. Downregulation of the Drosophila Immune Response by Peptidoglycan-Recognition Proteins SC1 and SC2. PLoS Pathog. 2006, 2, e14.

47. Charroux, B.; Capo, F.; Kurz, C.L.; Peslier, S.; Chaduli, D.; Viallat-Lieutaud, A.; Royet, J. Cytosolic and Secreted PeptidoglycanDegrading Enzymes in Drosophila Respectively Control Local and Systemic Immune Responses to Microbiota. Cell Host Microbe 2018, 23, 215-228. [CrossRef]

48. Dziarski, R.; Gupta, D. A balancing act: PGRPs preserve and protect. Cell Host Microbe 2018, 23, 149-151. [CrossRef]

49. Dolezal, T.; Krejcova, G.; Bajgar, A.; Nedbalova, P.; Strasser, P. Molecular regulations of metabolism during immune response in insects. Insect Biochem. Mol. Biol. 2019, 109, 31-42. [CrossRef] 